\title{
Outcome measures of disease activity in inflammatory arthritis
}

\author{
Geraint A Brown ${ }^{1}$, Alice Cotton ${ }^{1}$, Jesusa Guinto ${ }^{1}$, Arti Sharma ${ }^{1}$ and Coziana Ciurtin ${ }^{1}$ \\ ${ }^{1}$ Department of Rheumatology, University College London Hospital NHS Trust.
}

\begin{abstract}
:
The most common types of chronic inflammatory arthritis are rheumatoid arthritis (RA), psoriatic arthritis (PsA) and ankylosing spondylitis (AS). In order to assess the activity of these diseases and tailor therapy, several outcome measures have been developed. They include composite scores based on clinical findings, biochemical markers and patient questionnaires. This article aims to discuss the most commonly used outcome measures and discuss their limitations in quantifying the complex clinical features of different types of inflammatory arthritis, focusing in particular on RA, PsA and AS.
\end{abstract}

\section{Introduction:}

Inflammatory arthritis broadly encompasses rheumatoid arthritis (RA), psoriatic arthritis (PSA) and ankylosing spondylitis (AS). They are chronic autoimmune inflammatory conditions, which if left untreated lead to severe morbidity and increased mortality. One third of patients newly diagnosed with RA stop work within two years (Nice.org.uk). Early detection and aggressive immunosuppression with disease-modifying anti-rheumatic drugs (DMARDs) is required in order to achieve remission and reduce joint damage. To attain this goal and prevent the overuse of immunosuppressive medications, which have their own risks, several outcome measures assessing disease activity have been developed. The outcome measures used in rheumatologic practice frequently include composite scores, based on clinical findings, biochemical markers and patient reported outcome measures (PROMS). There are numerous outcome measures for RA, PsA and AS (Table 1). The purpose of this article is to discuss the most commonly used ones, including when they should be used in routine practise, their benefits and limitations.

\section{RA}

RA is a chronic systemic inflammatory disease characterised by multiple joint involvement. Its presentation is highly variable within individuals and between patients. Patients often experience significant joint pain, stiffness, fatigue and functional impairment. Since the first composite disease activity measurement tool was developed in the 1950s, researchers designed and validated another 63. Of these, the most commonly used and recommended by the American College of Rheumatology (ACR) and European League Against Rheumatism (EULAR), are:

1. Disease Activity Score with 28-joint counts (DAS28),

2. Clinical Disease Activity Index (CDAI),

3. Patient Activity Scale (PAS),

4. Routine Assessment of Patient Index Data 3 (RAPID3)

5. Simple Disease Activity Index (SDAI) (Anderson et al, 2012). 
These measurement tools can guide clinician treatment decision and indicate when clinical remission is reached.

The DAS28 score is the most recognised disease activity score and incorporates twenty eight joints that are assessed for tenderness and swelling (Figure 1). The patient is asked to score the severity of their disease (global health) on a scale of 0-100. Blood markers of inflammation (ESR or CRP) are incorporated and using these four variables, a complex mathematical formula is used to produce the overall disease activity score. A DAS28 score >5.1 implies active disease, a score between 3.2-5.1 signifies moderate disease activity, less than 3.2 equates to low disease activity, and $<2.6$ implies remission. A DAS 28 score should be performed on all patients with newly diagnosed RA, and this should be repeated at monthly treatment intervals until a low disease activity target is reached (Nice.org.uk). The National Institute for Health and Care Excellence (NICE) recommend that patients with a DAS28 score greater than 5.1 on two conventional DMARDs are eligible for biologic therapy.

The CDAl score incorporates the assessment of 28 joints for tenderness and swelling. The patient is asked to provide a global assessment of disease activity on a scale of 0-10, and the assessor grades the patient's global disease activity out of 10. All of the above values are added up to give a total score. Scores 22.1-76 equal high disease activity, 10.1-22 define moderate activity, 2.9-10 represent low disease activity, and 0-2.8 suggest remission (Rheumatology.org). This assessment tool is quick to use as it does not include inflammatory markers, and hence its use is particularly useful when no recent blood test results are available.

The SDAI score is similar to CDAI score except that it incorporates the patient's CRP value, which is assumed to be within the interval $0-10 \mathrm{mg} / \mathrm{dl}$. Therefore the maximum score is 86 . Once again, scores are grouped into remission, low, moderate and high disease activity (Rheumatology.org).

RAPID3 score is a patient reported outcome comprising numerous questions about the patients' function in the last week, their level of pain, and their global health. Scores are allocated depending on the patient's answers and are weighted. The maximum total score is 10 indicating high severity of disease if above 4, moderate severity if more than 2.3 and less than 4, and near remission if lower than 1 (Rheumatology.org). This assessment is quick to perform and can be completed by patients whilst awaiting their rheumatology consultation.

Another tool used for appreciation of disease severity in RA is PAS, which is a functional assessment of patient's everyday activities, walking ability and use of equipment aides, need for assistance, and level of pain over the last week.

The consensus is that the best outcome measure scores involve a combination of patient and physician assessments (Anderson et al, 2012). However, clinical assessment of disease performed by a trained health professional can be time consuming despite being more accurate and thus patient-reported outcome measures have been implemented in practice. It can be argued that by making patients responsible for their own assessment provides greater patient-centred care, and improves engagement and therapy compliance. A recent systematic review of PROMS used to assess disease activity in RA found that the patient derived disease activity score with 28 joint counts (Pt-DAS28), Rheumatoid Arthritis Disease activity index (RADAI) and RAPID 3 score had the strongest and most extensive validation (Hendrikx et al, 2016). 
The ACR criteria of response are the standard benchmarks used to measure the effectiveness of various DMARDs. There are three main criteria; designated as ACR 20, ACR 50 and ACR 70 response criteria. The numbers signify the percentage of improvement of disease activity between two discrete time points. The ACR criteria measure tender and swollen joints, patient and physician's disease activity assessments on a scale $0-10$, pain severity on scale $0-10$, disability/functional scores and inflammatory markers (ESR or CRP).

The EULAR response criteria classifies patients as either non-responders, moderate or good responders depending on two DAS28 scores taken between two discrete time points. The DAS28 score is a measure of disease activity at a certain time point rather than measurement of change such as the ACR response criteria (Fransen et al, 2005). Both assessments allow clinicians to determine whether certain treatments are effective or not. The ACR and EULAR criteria are therefore used in clinical trials and current practice, and when compared against each other, there was less than $3 \%$ discrepancy in their appreciation of patient response to treatment (van Gestel et al, 1999).

\section{AS}

AS is a chronic inflammatory disease of unknown aetiology characterised by inflammation of spinal joints and adjacent structures, which untreated leads to progressive bony fusion of the spine (Davis et al, 2005). AS has a genetic predisposition proven by its strong association with human leukocyte antigen B27 (HLA-B27).

The assessment of AS activity comprises objective signs of inflammation and assessment of the severity of patients' subjective symptoms. This includes the number of swollen and/or tender joints, the number of inflamed entheses, spinal pain, fatigue, and duration of morning stiffness. Laboratory markers of inflammation may be helpful, but are not incorporated in all outcome measure scoring systems used in AS, as they do not always correlate with the objective evidence of spinal inflammation. Outcome measures are important to guide for DMARD therapies selection in AS (van der Heijde et al 1997). Disease activity in AS is measured by several scores; the most used ones are detailed below.

The Bath Ankylosing Spondylitis Disease Activity Index (BASDAI) (Garett et al, 1994), (Figure 2) is a patient's reported outcome questionnaire using a visual analogue scale of 0 to 10 to assess the following criteria: A. fatigue, B. spinal pain, C. joint pain, D. enthesitis, E. qualitative morning stiffness and $F$. quantitative morning stiffness. The BASDAI score is calculated using the following formula: $B A S D A I=0.2(A+B+C+D+0.5[E+F])$. Patients who have a BASDAl score greater than 4 despite nonsteroidal anti-inflammatory drugs may be eligible for biological DMARD therapy.

The Bath Ankylosing Spondylitis Functional Index (BASFI) appreciates the physical function of patients with AS through a self-assessment questionnaire, and it is reported as mean score of 10 questions answered using a visual analogue scale 0 to 10 . Eight questions relate to patient's functional ability, and two questions relate to the patient's capacity to cope with everyday life. Any increase in the reposted score between two different time points indicates a worsening disease condition (Calin et al 1994).

The Bath Ankylosing Spondylitis Metrology Index (BASMI) is an aggregate score of five different objective measures of spinal mobility, which includes: lateral lumbar flexion, tragus-to-wall distance, lumbar flexion (modified Schober's test), intermalleolar distance and cervical rotation angle. Each 
parameter is calculated as a mean of right and left measurement. BASMI was used to determine the minimum number of clinically appropriate measurements that assess accurately axial mobility status to define clinically significant changes in spinal movement (van der Heijde et al, 2008).

The Maastrich Ankylosing Spondylitis Enthesitis Score (MASES index) (Heuft-Dorenbosch et al, 2003) was developed to assess enthesitis (inflammation of entheses) in patients with AS. The MASES index helps evaluate for the presence and absence of pain at the site of entheses, by applying local pressure to the following areas: $1^{\text {st }}$ costochondral joint (left and right), $7^{\text {th }}$ costochondral joint (left and right), posterior superior iliac spine (left and right), anterior superior iliac spine (left and right), iliac crest (left and right), $5^{\text {th }}$ lumbar spinous process, and proximal insertion of Achilles tendon (left and right). The range of MASES index is 0 to 13 .

\section{PsA}

PsA is a seronegative chronic inflammatory arthritis, which can manifest as peripheral joint inflammation, enthesitis, dactylitis and axial inflammation. Up to $40 \%$ of patients also have skin and nail involvement (Coates et al, 2012). Core outcome measures and domain sets have been set out by the collaborative research Group of Research and Assessment of Psoriasis and Psoriatic Arthritis (GRAPPA) and the Outcome Measures in Rheumatology group (OMERACT) (Mease, 2011). They have attempted to standardise measurements of disease used in randomised clinical trials to reflect both patients' and physicians' priorities. However, specific guidance for their use in the routine clinical rheumatology practice is lacking. There are few instruments specifically designed for measuring disease severity. Many outcome measures (such as peripheral joint disease, patient and physician global assessments, and axial disease) are adapted from the scores used in other similar conditions like RA and AS (Mease, 2011).

Evaluation of disease activity should include assessment of joints (peripheral arthritis, enthesitis, dactylitis, and spinal symptoms) and skin (severity of psoriasis, including psoriatic nail disease) (Gladman et al, 2004). Other domains include pain, patient and physician global assessment, physical function, HRQoL, fatigue and systemic inflammation (Orbai et al., 2016).

\section{Peripheral joint disease}

There are no widely validated and specific measures of peripheral joint disease for PsA (Gladman et al., 2007). In clinical practice, a 28 joint count as in RA is often performed. However, an extended joint count score assessing 66 joints for swelling, and 68 joints tenderness is frequently used in research settings (Gladman et al, 2007). The Psoriatic Response Criteria (PsARC), which was designed initially for a clinical trial of sulfasalazine, is another tool used for assessment of response to treatment in PsA; although not validated (Gladman et al, 2007). PsARC measures tender and swollen joint scores, physician global and patient global assessments of disease activity (0-5 point Likert scales). Overall improvement is defined as an improvement in minimum two of the four items, one of which must be joint count, without worsening of any items.

\section{Dactylitis}

Dactylitis, or sausage digit, is a hallmark clinical feature reported in $16-48 \%$ of PsA patients (Gladman et al, 2007). It is described as a uniform diffuse swelling of the soft tissues between metacarpophalangeal, proximal and distal interphalangeal joints - The Leeds Dactylitis Instrument 
(LDI) provides an objective assessment by measuring the diameter $(\mathrm{cm})$ for each digit affected and its tenderness score. A $10 \%$ difference in diameter between bilateral finger measurements indicates dactylitis. The LDI has demonstrated good inter- and intra-observer reliability and provides an objective measure of this feature (Gladman et al, 2007).

\section{Enthesitis}

Enthesitis is characterised as inflammation at the sites of tendon, ligament and joint capsule fibre insertion into the bone (Mease, 2011). Although enthesitis is a common feature of PsA, the enthesitis scores used in PsA have been adapted from AS. The Leeds Enthesitis Index (LEI) assesses the presence or absence of tenderness on palpation at six keys sites: both lateral epicondyles; medial epicondyles; and Achilles tendons. The LEI score showed good sensitivity to change following effective treatment (Gladman et al, 2007).

\section{Axial disease}

Incidence of spinal involvement in PsA is reported between 20-70\% patients (Gladman et al, 2007). Although axial disease is considered to be less severe in PsA patients compared to AS patients, many of the outcome measures used in AS are applicable to PsA.

\section{Nail disease}

Psoriatic nail changes are associated with higher joint counts and disease activity (Sandre, Rohekar and Guenther, 2015). The Nail Psoriasis Severity Index (NAPSI) is a simple objective tool to evaluate changes in colour, the thickness and features of the nail plate and matrix (Gladman et al, 2007). Features of nail psoriasis include nail pitting, crumbling, onycholysis, oil drop dyschromia, splinter haemorrhages, leukonychia, and red spots (Figure 3). The modified NASPI score (m-NAPSI), improved following GRAPPA focus group discussions have enhanced its feasibility and face validity.

\section{Skin Assessment}

Skin assessment is not a direct measure of PsA activity in rheumatology settings, as psoriasis is only present in $40 \%$ of PsA patients. The Psoriasis area and severity index (PASI) is the most widely used assessment tool for skin psoriasis (Mease, 2011). It measures the erythema, induration, scale and area affected by psoriasis, and can be re-measured at regular intervals to evaluate the effectiveness of treatment (Hughes and van Onselen, 2001). Rheumatologists often use subjective measures including patient and physician global assessment of psoriasis disease activity, comprising of visual analogue scales (VAS).

\section{Conclusions:}

Disease activity measuring tools allow clinicians to assess the severity of rheumatic conditions, which can act as guidance on when to escalate/reduce medical therapy. Low disease activity scores indicate disease remission, providing reassurance to the clinician that the risk of long-term irreversible joint damage is significantly reduced. They play an important role in research studies as a standardised assessment tools, allowing potential new therapies to be compared to current treatment. Composite outcome measures can also offer information about disease impact on patient's quality of life. These assessments can support clinicians in involving members of the multi-disciplinary team in the provision 
of patient's care, ultimately improving patient outcomes. Patients can also complete some assessment tools before seeing a rheumatologist, therefore maximising the time and quality of the consultation.

However, these tools have their limitations. Firstly, patient's scores often include pain as a reported outcome, which is subjected to wide variations in patient's perceptions of pain. A stoical patient's pain score will significantly underestimate underlying disease activity, as opposed to a patient with a low pain threshold. Those patients with multiple co-morbidities are also difficult to assess clinically, as how they feel may be related to several conditions as opposed to just their underlying rheumatic disease. The same applies to those with chronic pain/fibromyalgia. Secondly, there can be variations between assessors in their perception of swollen and pressure applied to elicit joint tenderness, depending on the level of skills and experience of the assessor.

Inflammatory arthropathies encompass a wide variety of presentations that pose challenges in assessing overall disease activity. An objective measure may assess a single aspect of the disease but does not include the psychological impact of the disease on patient's quality of life. The Health assessment questionnaire (HAQ) is recommended by NICE for use in practice, as it identifies physical limitations of everyday tasks. It should be performed every 6 or 12 months. Another patient questionnaire, the Quality of Life Index is a very useful tool to assess psychological well-being, as depression is common in patients with arthritis. Radiographic damage scores also have a role as outcome measures in arthritis, and it is useful to request x-rays at the time of diagnosis, with further imaging performed when new symptoms arise or at set time points, to identify irreversible joint changes that would suggest ongoing chronic inflammation. There is also an emerging role in the use of joint ultrasound examination in patients with RA and PsA, which can detect sub-clinical synovitis. Composite scores, combining clinical and imaging outcomes are likely to become more common.

Overall, there is no doubt that disease activity measuring tools are of significant benefit, and allow quantification and comparisons between patient's disease activity levels over time and between larger populations. We recommend regular use of DAS28, PSARC and BASDAI in follow-up appointments for inflammatory arthritis patients, as validated scores that were shown to improve therapeutic decisions and disease control over time, were associated with a significant patient benefit.

Table 1: Outcome measures for inflammatory arthritis

\begin{tabular}{|l|c|c|c|}
\hline $\begin{array}{c}\text { Type of } \\
\text { inflammatory } \\
\text { arthritis }\end{array}$ & Rheumatoid arthritis & Psoriatic arthritis & Ankylosing spondylitis \\
\hline $\begin{array}{l}\text { Peripheral } \\
\text { joint } \\
\text { involvement }\end{array}$ & $\begin{array}{c}\text { Tender joint count (TJC/28 } \\
\text { or } 44 \text { or 68) }\end{array}$ & $\begin{array}{c}\text { Tender joint count } \\
\text { (TJC/68) }\end{array}$ & $\begin{array}{c}\text { Tender joint count } \\
\text { (TJC/68) }\end{array}$ \\
& $\begin{array}{c}\text { Swollen joint count (SJC/28 } \\
\text { or 44 or 66) }\end{array}$ & $\begin{array}{c}\text { Swollen joint count } \\
\text { (SJC/66) }\end{array}$ & $\begin{array}{c}\text { Swollen joint count } \\
\text { (SJC/66) }\end{array}$ \\
& $\begin{array}{c}\text { Physician global rating (VAS) } \\
\text { Patient global rating (VAS) }\end{array}$ & $\begin{array}{c}\text { Physian global rating } \\
\text { (Likert's scale) }\end{array}$ & $\begin{array}{l}\text { Enthesitis (LEI, MASES, } \\
\text { MEI, enthesitis question } \\
\text { on BASDAI) }\end{array}$ \\
\hline
\end{tabular}




\begin{tabular}{|c|c|c|c|}
\hline & $\begin{array}{c}\text { Patient pain rating (VAS) } \\
\text { DAS } 28 \\
\text { CDAI } \\
\text { SDAI } \\
\text { RAPID } 3 \\
\text { ACR20 } \\
\text { ACR } 50 \\
\text { ACR } 70 \\
\text { EULAR and ACR response } \\
\text { criteria } \\
\text { Boolean remission criteria } \\
\text { Inflammatory markers } \\
\text { Radiographic progression } \\
\text { (Steinbrocker, Sharp/Larsen } \\
\text { scores) } \\
\text { MRI progression (RAMRIS } \\
\text { score) }\end{array}$ & $\begin{array}{c}\text { Patient global rating } \\
\text { (Likert's scale) } \\
\text { DAS } 28 \\
\text { ACR20 } \\
\text { ACR } 50 \\
\text { ACR } 70 \\
\text { EULAR and ACR } \\
\text { response criteria } \\
\text { Dactylitis (LDI) } \\
\text { Enthesitis (LEI, MASES) } \\
\text { Nail disease (NAPSI) } \\
\text { Inflammatory markers } \\
\text { Radiographic } \\
\text { progression (modified } \\
\text { Steinbrocker, } \\
\text { Sharp/Larsen, PARS } \\
\text { scores) } \\
\text { MRI progression } \\
\text { (PsAMRIS score) }\end{array}$ & $\begin{array}{c}\text { Radiographic } \\
\text { progression } \\
\text { (Steinbrocker, } \\
\text { Sharp/Larsen scores) }\end{array}$ \\
\hline $\begin{array}{l}\text { Axial Joint } \\
\text { involvement }\end{array}$ & N/A & $\begin{array}{l}\text { BASDAI } \\
\text { BASFI } \\
\text { BASMI } \\
\text { Spinal pain (VAS) } \\
\text { ASDAS } \\
\text { ASAS 20,50,70 } \\
\text { Spinal stiffness } \\
\text { (stiffness question on } \\
\text { BASDAI) } \\
\text { Spinal enthesitis (MEI) } \\
\text { Inflammatory markers }\end{array}$ & $\begin{array}{l}\text { BASDAI } \\
\text { BASFI } \\
\text { BASMI } \\
\text { Spinal pain (VAS) } \\
\text { ASDAS } \\
\text { ASAS 20,50,70 } \\
\text { Spinal stiffness (stiffness } \\
\text { question on BASDAI) } \\
\text { Spinal enthesitis (MEI) } \\
\text { Inflammatory markers }\end{array}$ \\
\hline
\end{tabular}




\begin{tabular}{|c|c|c|c|}
\hline & & $\begin{array}{l}\text { Radiographic } \\
\text { progression (mSASSS) } \\
\text { MRI progression } \\
\text { (ASspiMRI-a, Berlin and } \\
\text { SPARCC scores) }\end{array}$ & $\begin{array}{l}\text { Radiographic } \\
\text { progression (mSASSS) } \\
\text { MRI progression } \\
\text { (ASspiMRI-a, Berlin and } \\
\text { SPARCC scores) }\end{array}$ \\
\hline $\begin{array}{l}\text { Quality of life } \\
\text { outcome } \\
\text { measures }\end{array}$ & $\begin{array}{l}\text { HAQ } \\
\text { SF-36 } \\
\text { EuroQol-5D }\end{array}$ & $\begin{array}{l}\text { HAQ } \\
\text { PSAQoL } \\
\text { SF-36 } \\
\text { EuroQol-5D }\end{array}$ & $\begin{array}{l}\text { HAQ } \\
\text { SF-36 } \\
\text { EuroQol-5D } \\
\text { ASQOL }\end{array}$ \\
\hline
\end{tabular}

ASDAS = Ankylosing Spondylitis Disease Activity Score

ASQOL = Ankylosing Spondylitis Quality of Life

ASAS $=$ Assessment of Spondyloarthritis

ASspiMRI-a = Ankylosing Spondylitis spine Magnetic Resonance Imaging-activity

EuroQol-5D = European Quality of Life 5 Domain score

$\mathrm{HAQ}=$ Health Assessment Questionnaire

LDI = Leeds Dactyitis Score

LEI = Leeds Enthesitis Index (6 points)

MASES = Maastricht Ankylosing Spondylitis Enthesitis Score (13 points)

MEI = Maastricht Ankylosing Spondylitis Enthesitis Score (66 points)

mSASSS $=$ modified Stoke Ankylosing Spondylitis Spine Score

PARS $=$ Psoriatic Arthritis Ratingen Score

PsAMRIS = Psoriatic arthritis- MRI scoring system

PsAQoL = Psoriatic Arthritis Assessment of Quality of Life

RAMRIS = Rheumatoid Arthritis-MRI scoring system

SF-36 $=$ Medical Outcomes Study Short Form 36

SPARCC $=$ Spondyloarthritis Research Consortium of Canada 
Figure 1: Disease Activity Score with 28-joint counts

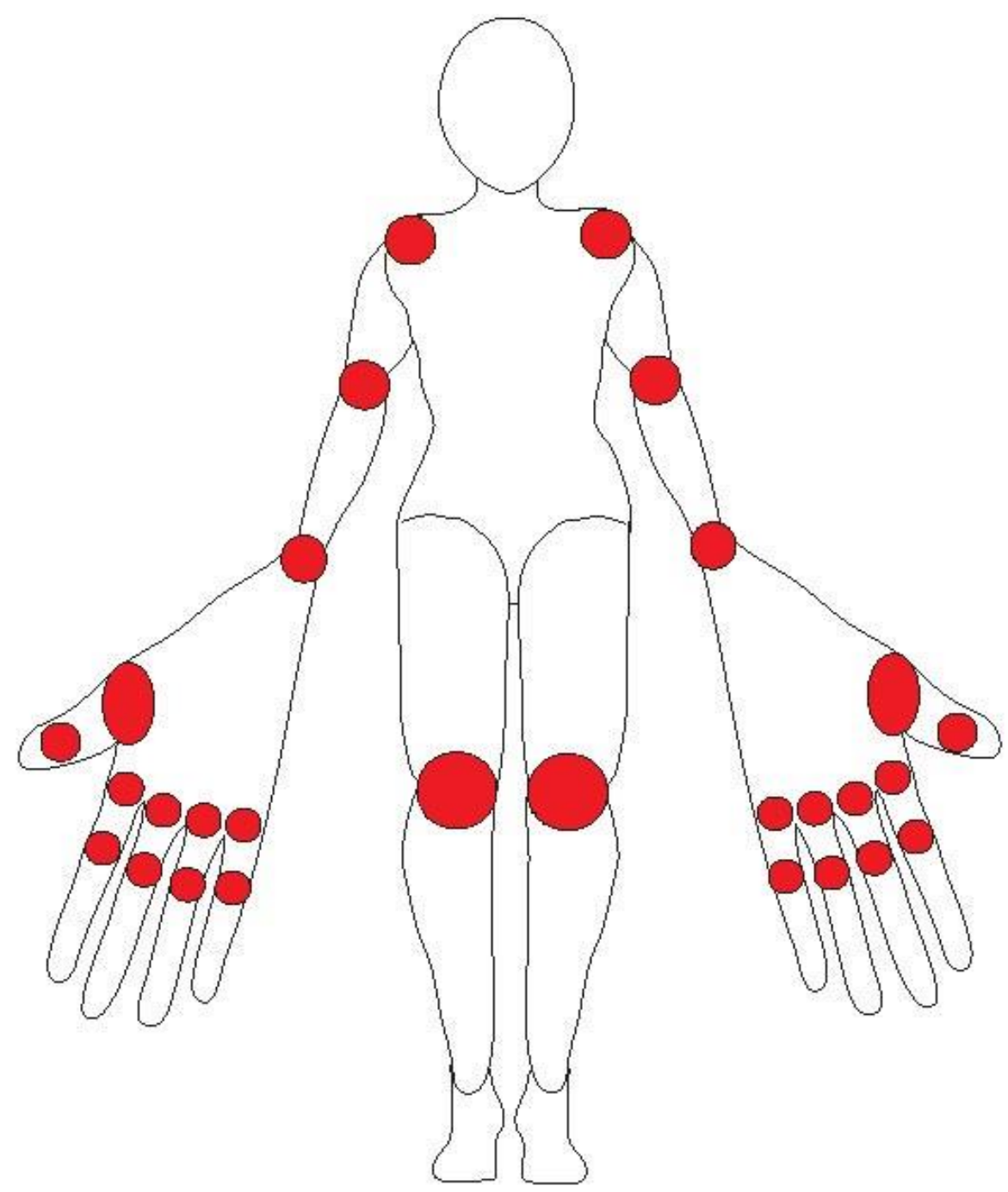

Figure 2: Bath Ankylosing Spondylitis Disease Activity Index (BASDAI) Garrett et al. J Rheumatol 1994 21; 2286-91

Please tick the box which represents your answer. All questions refer to past week.

1. How would you describe the overall level of fatigue/tiredness you have experienced?

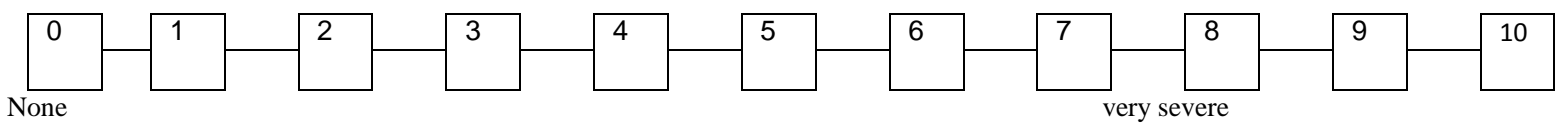

2. How would you describe the overall level of AS neck, back or hip pain you have had?

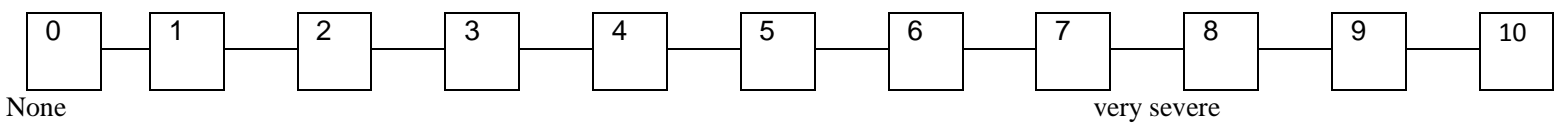

3. How would you describe the overall level of pain/swelling in joints other than neck, back, hips you have had?

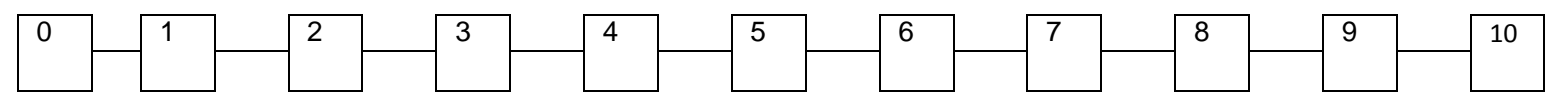


4. How would you describe the overall level of discomfort you have had from any areas tender to touch or pressure?

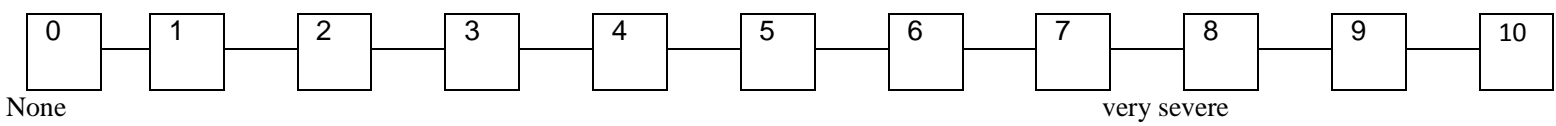

5. How would you describe the overall level of morning stiffness you have had from the time you wake up?

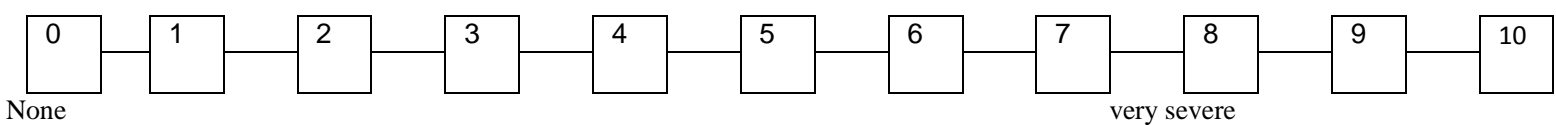

6. How long does your morning stiffness last from the time you wake up?

0 hrs $\quad 1 / 2 \quad 11 \frac{11 / 2}{2} \quad$ or more hours

Please add the scores (take the mean of stiffness questions $5 \& 6$ ) to give a score out of 50 . Then multiply by 2 and divide by 10 to give a total BASDAl out of 10 .

Figure 3: Two psoriatic nails with pitting, crumbling, and onycholysis.

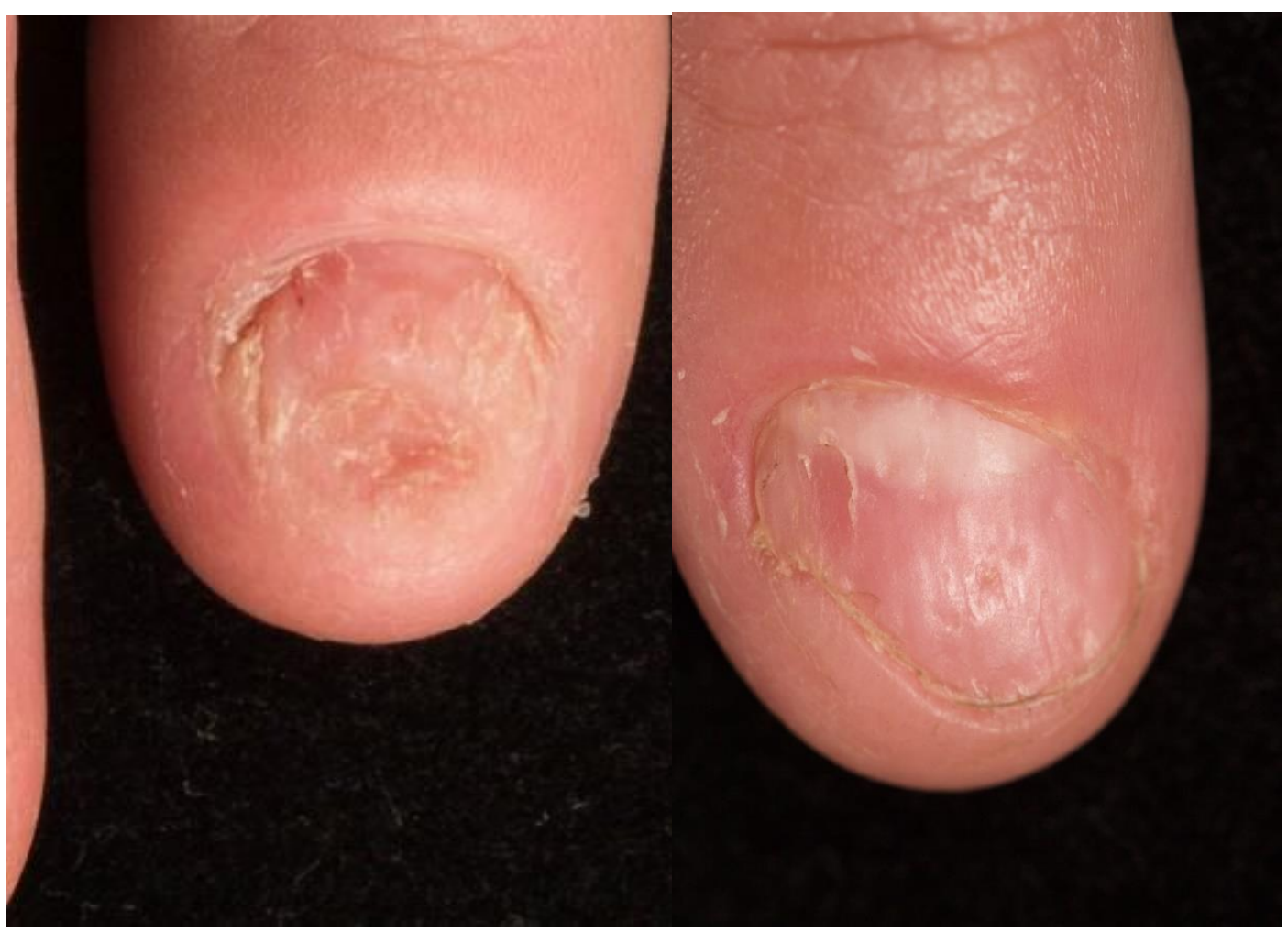




\section{References:}

Anderson J, Caplan L, Yazdany J, et al. (2012) Rheumatoid arthritis disease activity measures: American College of Rheumatology recommendations for use in clinical practice. Arthritis Care Res 64 (5): 640647.

Calin A, Garett SL, Jenkinson TR, et al. (1994) A new approach to defining functional ability in ankylosing spondylitis: the development of the Bath Ankylosing Spondylitis Functional Index (BASFI). J Rheumatol 21:2281-2285.

Coates LC, Tillett W, Chandler D, et al. (2013) The 2012 BSR and BHPR guideline for the treatment of psoriatic arthritis with biologics. Rheumatol 52 (10):1754-1757.

Davis Jr JC (2005) Ankylosing Spondylitis. Arthritis and allied conditions, Lippincott Williams \& Wilkins.

Fransen J, van Riel PLCM. (2005) The disease activity score and the EULAR response criteria. Clin Exp Rheumatol 23(39):93-99.

Garett S, Jenkinson T, Kennedy LG, Whitelock H. Gaisford P, Calin A. (1994) A new approach to defining disease status in ankylosing spondylitis: The Bath Ankylosing Spondylitis Disease Activity Index. J Rheumatol 21(12):2286-2291.

Gladman DD, Cook RJ, Schentag C, et al. (2004) The clinical assessment of patients with psoriatic arthritis: results of a reliability study of the spondyloarthritis research consortium of Canada. $J$ Rheumatol 31(6):1126-31.

Gladman DD, Mease PJ, Healy P, et al. (2007) Outcome measures in psoriatic arthritis. J Rheumatol 34(5): 1159-1166.

Heijde van der D, Bellany N, Calin A, Dougados M, Khan MA, Linden van der S (1997) Assessments in Ankylosing Spondylitis Working Group. Preliminary core sets for endpoints in ankylosing spondylitis. J Rheumatol, 24:2225-2229.

Hendrikx J, de Jonge MJ, Fransen J, Kievit W, and van Riel PL. (2016) Systematic review of patientreported outcome measures (PROMs) for assessing disease activity in rheumatoid arthritis. RMD Open 2016 Aug 18; 2(2).

Heuft-Dorenbosch L, Spoorenberg A, van Tuburgen A, et al. (2003) Assessment of enthesitis in ankylosing spondylitis. Ann Rheum Dis 62(2):127-132.

Hughes E and van Onselen J (2001). Dermatology Nursing, A Practical Guide. Edinburgh: Churchill Livingston.

Mease PJ (2011) Measures of psoriatic arthritis: Tender and Swollen Joint Assessment, Psoriasis Area and Severity Index (PASI), Nail Psoriasis Severity Index (NAPSI), Modified Nail Psoriasis Severity Index (mNAPSI), Mander/Newcastle Enthesitis Index (MEI), Leeds, Arthritis Care Res 63(11):64-85.

NICE.org.uk 
Orbai AM, Mease PJ, de Wit M, et al. (2016) Report of the GRAPPA-OMERACT Psoriatic Arthritis Working Group from the GRAPPA 2015 Annual Meeting, J Rheumatol 43(5):965-969.

Rheumatology.org

Sandre MK, Rohekar S, and Guenther L (2015) Psoriatic Nail Changes Are Associated With Clinical Outcomes in Psoriatic Arthritis. J Cutan Med Surg 19(4):367-76.

Van der Heijde D, Landewé R, Feldtkeller E. (2008) Proposal of a linear definition of the Bath Ankylosing Spondylitis Metrology Index (BASMI) and comparison with the 2-step and 10-step definition. Ann Rheum Dis 67:489-493.

Van Gestel AM, Anderson JJ, van Riel PL, Boers M, et.al. (1999) ACR and EULAR improvement criteria have comparable validity in rheumatoid arthritis trials. J Rheumatol 26:705-711. 